\title{
Berry composition and climate: responses and empirical models
}

\author{
Nyamdorj N. Barnuud • Ayalsew Zerihun • \\ Mark Gibberd • Bryson Bates
}

Received: 22 November 2012 / Revised: 28 July 2013 / Accepted: 31 July 2013 / Published online: 20 August 2013

(C) The Author(s) 2013. This article is published with open access at Springerlink.com

\begin{abstract}
Climate is a strong modulator of berry composition. Accordingly, the projected change in climate is expected to impact on the composition of berries and of the resultant wines. However, the direction and extent of climate change impact on fruit composition of winegrape cultivars are not fully known. This study utilised a climate gradient along a $700 \mathrm{~km}$ transect, covering all wine regions of Western Australia, to explore and empirically describe influences of climate on anthocyanins, $\mathrm{pH}$ and titratable acidity (TA) levels in two or three cultivars of Vitis vinifera (Cabernet Sauvignon, Chardonnay and Shiraz). The results showed that, at a common maturity of $22^{\circ}$ Brix total soluble solids, berries from the warmer regions had low levels of anthocyanins and TA as well as high $\mathrm{pH}$ compared to berries from the cooler regions. Most of these regional variations in berry composition reflected the prevailing climatic conditions of the regions. Thus, depending on cultivar, 82 $87 \%$ of TA, $83 \%$ of anthocyanins and about half of the $\mathrm{pH}$ variations across the gradient were explained by climatevariable-based empirical models. Some of the variables that were relevant in describing the variations in berry attributes included: diurnal ranges and ripening period temperature (TA), vapour pressure deficit in October and growing degree days $(\mathrm{pH})$, and ripening period temperatures (anthocyanins). Further, the rates of change in these berry attributes in response to climate variables were cultivar dependent. Based on the observed patterns along the climate gradient, it is concluded that: (1) in a warming climate, all other things being equal, berry anthocyanins and TA levels will decline whereas $\mathrm{pH}$
\end{abstract}

\footnotetext{
N. N. Barnuud $\cdot$ A. Zerihun $(\triangle) \cdot$ M. Gibberd

Department of Environment and Agriculture, Curtin University, Margaret River Education Campus, Margaret River, WA 6285, Australia

e-mail: a.zerihun@curtin.edu.au

B. Bates

Centre for Environment and Life Sciences, CSIRO, Underwood Avenue, Floreat, WA 6014, Australia
}

levels will rise; and (2) despite variations in non-climatic factors (e.g. soil type and management) along the sampling transect, variations in TA and anthocyanins were satisfactorily described using climate-variable-based empirical models, indicating the overriding impact of climate on berry composition. The models presented here are useful tools for assessing likely changes in berry TA and anthocyanins in response to changing climate for the wine regions and cultivars covered in this study.

Keywords Anthocyanins · Cabernet Sauvignon · Chardonnay · Climate gradient - Titratable acidity · Models . $\mathrm{pH} \cdot$ Shiraz $\cdot$ Titratable acidity $\cdot$ Vitis vinifera $\mathrm{L}$.

\section{Introduction}

The quality of berries and of the subsequent wine is influenced strongly by chemical constituents and their concentration at harvest (Coombe et al. 1980; Fontoin et al. 2008; Herderich and Smith 2005). Berry composition is influenced by factors such as climate, genotype, management, and soil type (Gladstones 1992; Jackson and Lombard 1993). When other factors are held comparatively constant, climate is the dominant factor that influences berry and wine quality (Ashenfelter 2008; Jones and Storchmann 2001; Makra et al. 2009; Storchmann 2005). Of the climate variables, temperature has been recognised as a primary driver of vine growth and berry/ wine composition (Gladstones 1992; Soar et al. 2008; Winkler 1974). For example, Petrie and Sadras (2008) utilised between-season variation to demonstrate that higher growing season temperature resulted in increased rates of sugar accumulation and advanced fruit maturity dates. Furthermore, Sadras et al. (2007a) demonstrated a negative relationship between the rate of change in red wine quality (as assessed by vintage scores) during 1980 to 2005 for Australian wine regions and average temperatures during the month before harvest; however, no trend was evident for white wines. 
Viticulture is a sector vulnerable to climate change due to the sensitivity of grapevine phenology and fruit composition to temperature. However, impacts of climate warming on viticulture remain unclear as research results based on historical data generate conjecture. For example, Nemani et al. (2001) speculated that, while climate warming during the period from 1965 to 1996 had positive effects on yield and wine quality in the Sonoma and Napa Valleys, further warming may have unfavourable impacts on the Californian wine industry due to the increase in fungal disease under elevated temperature and humidity. Similarly, based on predictions that used empirical yield and a climate model, Lobell et al. (2006) indicated potential yield loss of perennial crops in California. In contrast, Jones et al. (2005) explored the relationships between optimum growing season temperature and vintage score (a surrogate for wine quality), and predicted uneven impacts of climate change on wine quality across the world's wine regions depending on current growing season temperature and future warming.

Australian studies generally suggest a negative impact of climate change. For example, a study that broadly examined six Australian wine regions predicted a shortened growing season (Webb et al. 2007). According to this study, all regions, except Margaret River, are predicted to have earlier budburst and harvest dates in the coming decades. Webb et al. (2008a, b) also argue that, although there is likely to be variation in the sensitivity to climate change among winegrape cultivars, without adaptive measures winegrape quality in Australia will generally decrease. A more recent study (Hall and Jones 2009) concluded that the number of current wine growing regions with unsuitable growing season temperatures for quality wine production will increase as a result of climate change.

Plant growth and development are often influenced by interactions among different climate variables. Therefore, inferences derived from relationships between an individual climate variable and grape attribute may not necessarily be the same when the effects of other climate variables are taken together under real conditions. Plant physiological and mechanistic models, such as VineLogic (Godwin et al. 2002), would help to address such interactions provided the models have an adequate choice of inputs to simulate the whole system under consideration. However, to our knowledge, there are no readily available mechanistically parameterised models for simulating berry quality responses under climate change scenarios. Instead, empirical models have been used to investigate climate influences on berry growth and development and/or for evaluating the climate change impacts on viticulture (Ashenfelter 2008; Jones and Davis 2000; Lobell et al. 2006). For this study, we employed an empirical modelling approach to examine the combined effects of multiple climate variables on berry anthocyanins, $\mathrm{pH}$ and TA levels.

To date all studies that have attempted to evaluate the effects of climate change on berry and/or wine composition have relied on proxy measures such as grape price (Webb et al. 2008 b) or vintage scores (Jones et al. 2005; Sadras et al. 2007a). While these studies are valuable in providing a generalised picture, the observation that different winegrape cultivars exhibit differential sensitivity to climate (e.g. Webb et al. 2008a) means that generalised projections based on indirect measures have limited value in predicting the responses of specific cultivars. The underlying reason for using proxy variables as quality indicators is the absence of directly measured berry quality attribute data on responses of some of the major winegrape cultivars to climate change. The work reported here was designed to fill this gap. Such data will be important in adaptation strategie, e.g. in decision making with regard to matching cultivars with sites. The aims of this work were to: (1) determine the responses of some key berry attributes [anthocyanins, titratable acidity (TA) and $\mathrm{pH}$ ] that are influential for wine quality to changing levels of climate variables; and (2) develop empirical models that adequately describe the responses. The study was carried out in commercial vineyards located along a well-defined climate gradient, and included the major winegrape cultivars (Cabernet Sauvignon, Shiraz and Chardonnay) currently grown in Australia.

\section{Materials and methods}

Monitoring sites and plant material

Ten commercial vineyards covering all the major wine regions of Western Australia (Fig. 1) were used to monitor the dynamics of TA, pH and total anthocyanins in Cabernet Sauvignon and Shiraz grapes; and of TA and $\mathrm{pH}$ in Chardonnay grapes. Monitoring was carried out from veraison until berry total soluble solids (TSS) reached $22^{\circ}$ Brix during the 2008-2009 (Season 1, hereafter) and 2009-2010 (Season 2 , hereafter) growing seasons. The ten study vineyards lie along a $700 \mathrm{~km}$ north-south transect with an average (19762005) growing season temperature (October-April) that ranged from $17.8{ }^{\circ} \mathrm{C}$ at the southernmost site to $22.9^{\circ} \mathrm{C}$ at the northernmost vineyard site.

In this study, influences of climate variables on berry composition were examined at a TSS maturity of $22^{\circ}$ Brix for pragmatic reasons. It is acknowledged, however, that in practice, while the level of TSS is used as an indicator of berry maturity, even when a crop is 'sugar ripe', the decision when to harvest may vary for several reasons including intended wine style, perceived flavour and/or aroma balance, and logistics. The variable length of time a crop stays on the vine can influence berry composition. This additional source of variation can be minimised when comparisons are made at a common maturity level. Our aim was to tease out the effects climate variables on berry quality attributes by removing 
Fig. 1 Map of study areas in Western Australia. Numbered dots in enlarged picture represent study site locations. OctoberApril average temperature, average annual rainfall, and dominant soil types for each site are indicated in parentheses. Climate data (average for the 1976-2005 period) was obtained from SILO DataDrill database (Jeffrey et al. 2001)

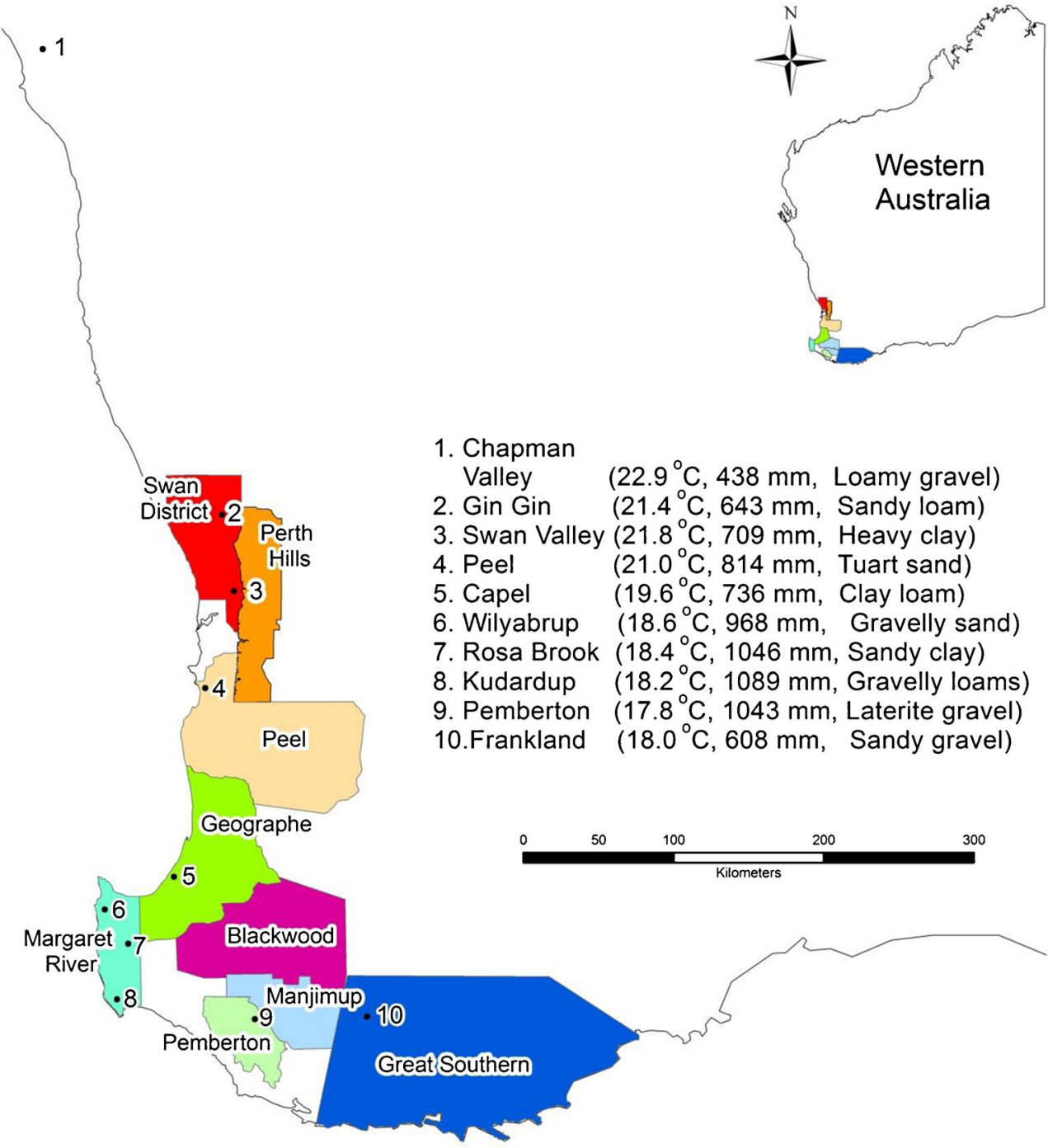

confounding factors such as those of winemakers' decisions of when to harvest by fixing maturity to when the crop first reaches $22^{\circ}$ Brix TSS.

It is also acknowledged that differences in vineyard management practices and properties of plant material across different sites can contribute to variations in fruit composition. However, it was not feasible to utilise monitoring sites with identical planting material and management practices along the entire transect. Most of the sites in this study had vertical shoot positioning (VSP) training and spur pruning, except at the Capel, Willyabrup (both had T-trellis) and Frankland (bilateral) sites. Similarly, the cultivars were planted mainly on their own-roots except Chardonnay at Gin Gin (which was grafted onto Chenin Blanc), Shiraz and Chardonnay (on Schwarzmann) at Swan Valley and Cabernet Sauvignon and Chardonnay (on Schwarzmann) at Pemberton. The vines were between 5 and 25 years old (Table 1). The soil types also varied across sites (Fig. 1).
Bunch sampling

Ten bunches of grapes from ten vines, five from one side of a row and the others from the opposite side of the row, were sampled randomly for each cultivar at weekly intervals between the start of veraison and the berry TSS maturity of $22^{\circ}$ Brix (common maturity, hereafter). The ten sample vines were also selected randomly from four rows in the middle of a block to avoid edge effects and in such a way that no vines were sampled twice during the sampling period. Sampled bunches were placed in a chilled box and taken to the laboratory for berry composition analysis.

Berry composition analysis

A quarter of the berries was gently stripped from all parts of the sampled bunches. Half of the berries were placed in a plastic container and kept frozen for anthocyanin analysis. 
Table 1 Vine ages, training systems and average yields for the study sites. Data were provided by vineyard owners. VSP Vertical shoot positioning

\begin{tabular}{|c|c|c|c|c|c|c|c|c|c|}
\hline \multirow[t]{2}{*}{ Site } & \multicolumn{3}{|l|}{ Shiraz } & \multicolumn{3}{|c|}{ Cabernet Sauvignon } & \multicolumn{3}{|l|}{ Chardonnay } \\
\hline & Age (years) & Training & Yield (t/ha) & Age (years) & Training & Yield (t/ha) & Age (years) & Training & Yield (t/ha) \\
\hline Chapman Valley & 10 & VSP & $5.5-6.0$ & 10 & VSP & $4.5-5.0$ & $-{ }^{\mathrm{a}}$ & - & - \\
\hline Gin Gin & 5 & VSP & 1.0 & 5 & VSP & 1.0 & 5 & VSP & 1.3 \\
\hline Swan Valley & 20 & VSP & n.a. ${ }^{\mathrm{b}}$ & - & - & - & 5 & VSP & $3.7-4.0$ \\
\hline Peel & 25 & VSP & n.a. & 25 & VSP & n.a. & 25 & VSP & n.a \\
\hline Capel & 20 & T-trellis & $9.5-10.9$ & 20 & T-trellis & $8.4-9.0$ & 20 & T-Trellis & $7.9-12.6$ \\
\hline Wilyabrup & Unknown & VSP & n.a & Unknown & T-trellis & $10.1-12.3$ & Unknown & VSP & $5.9-9.0$ \\
\hline Rosa Brook & 11 & VSP & 6.4 & 14 & VSP, spur & 3.04 & 11 & VSP & 4.0 \\
\hline Kudardup & - & - & - & 8 & VSP, spur & n.a. & 8 & VSP & n.a. \\
\hline Frankland & 10 & Bi-lateral & 5.7 & 10 & Bi-lateral & 5.7 & 10 & Bi-lateral & 4.5 \\
\hline Pemberton & 11 & VSP & $5.2-9.2$ & 17 & VSP & $2.7-6.8$ & 18 & VSP, spur & $4.9-6.2$ \\
\hline
\end{tabular}

${ }^{a}$ Indicates that the particular variety was not available on that vineyard for sampling

${ }^{\mathrm{b}}$ Data not available

The remaining berries were placed in a plastic bag and crushed by hand without cracking the seeds and the juice was used for TSS, $\mathrm{pH}$ and TA analysis. Juice from the hand-crushed berries was centrifuged at $1,349 \mathrm{~g}$ for $10 \mathrm{~min}$. The supernatant was used to determine TSS with a temperature-compensated digital refractometer (Reichert AR200, Reichert, Depew, NY) and reported in ${ }^{\circ}$ Brix at $20{ }^{\circ} \mathrm{C}$. Juice $\mathrm{pH}$ and TA were measured with a $\mathrm{pH}$ meter. Titratable acidity was determined by titrating juice samples against $0.1 \mathrm{M} \mathrm{NaOH}$ solution to an endpoint of $\mathrm{pH}$ 8.2. Results are expressed as grams of tartaric acid equivalents per litre of juice $(\mathrm{g} / \mathrm{L})$.

Anthocyanins were extracted and analysed as described in Iland et al. (2004). Briefly, after thawing frozen samples, 50 berries were selected randomly and weighed. These were homogenised (Ultra Turrax T25 Basic, IKA, Staufen, Germany) at 24,000 rpm until the sample became a smooth paste. Approximately $1 \mathrm{~g}$ homogenate was weighed into a centrifuge tube and $10 \mathrm{ml} 50 \%$ aqueous ethanol $(\mathrm{pH} 2)$ was added. The homogenate-ethanol mixture was agitated continuously for $10 \mathrm{~min}$ to facilitate extraction of anthocyanins. The samples were then centrifuged at $1,349 \mathrm{~g}$ for $5 \mathrm{~min}$. A subsample of the supernatant was diluted 1:10 with $1 \mathrm{M} \mathrm{HCl}$. After $3 \mathrm{~h}$, absorbance values of the diluted samples were recorded at $520 \mathrm{~nm}$ with a spectrophotometer. Anthocyanins results are expressed as mg malvidin-3-glucoside equivalents per gram berry weight $(\mathrm{mg} / \mathrm{g})$.

Meteorological and climate data

Temperature was measured at 15 -min intervals during the postveraison to harvest period (shielded Tinytag TG-0050, Gemini Data Loggers, Chichester, UK) at each site. The sensors and loggers were installed on posts (about $1.6 \mathrm{~m}$ above ground level) in a clear area within $20 \mathrm{~m}$ of the study vineyards' edges.
In addition, daily data for each site for other variables such as rainfall, radiation, evaporation, and moisture were purchased from the SILO data drill database (Jeffrey et al. 2001). Values of these variables for the growing season and the veraison to maturity period were calculated separately for each cultivar and season since the growing season lengths were different for each cultivar and/or season. For this study, the growing season was defined as the period between October and the date when fruit reached common maturity. The ripening period and the veraison to maturity period were defined as the 30-day period preceding common maturity (see also Gladstones 2011) and the period between the beginning of veraison and the designated common maturity date, respectively.

\section{Data standardisation}

Due to the weekly sampling interval, some samples were not exactly at a TSS of $22^{\circ}$ Brix (common maturity) on the sampling dates. For this reason, a linear interpolation was carried out to estimate levels of TA, anthocyanins and $\mathrm{pH}$ for those samples whose TSS values varied by more than $0.2^{\circ}$ Brix from common maturity. Common maturity was interpolated from a linear regression between accumulated biologically effective degree days (difference between the daily average temperature capped at $19^{\circ} \mathrm{C}$ and a base of $10{ }^{\circ} \mathrm{C}$ ) (Gladstones 1992) and the TSS values of two consecutive samples that enveloped the targeted common maturity. Overall, the variation between the interpolated common maturity TSS and actual values across sites and cultivars differed by less than $0.6^{\circ}$ Brix units.

Selection of climate variables

While temperature, rainfall and radiation are the basic components of climate that affect plant growth and development, 
variables derived from these may also influence berry composition. Thus, an a priori list of the basic variables and derivatives thereof that can potentially affect berry composition was compiled (Table 2), and their values computed for the entire or specific periods of the growing season. This exercise generated more than 70 variables (Table 2). Durations (h) over $25^{\circ} \mathrm{C}$ and $30^{\circ} \mathrm{C}$ during fruit ripening were estimated from the logged temperature on vineyard sites. In the warmer sites, berries attained the common maturity level in February; hence, data beyond this time were not included in the analyses reported here. Thus, although the growing season for the southern hemisphere is nominally defined from October to April, in this work the growing season ranges from October to the time berries reached the defined common maturity. October to March average temperature differences between the warmest and coolest sites were over $5{ }^{\circ} \mathrm{C}$ for both seasons (Table 3). There were also considerable differences between sites in rainfall (10-fold in Season 1 and 3-fold in Season 2). However, the berry ripening periods were virtually rain-free, and all sites used supplementary irrigation.

\section{Data analysis}

The relationships of TA, anthocyanins and $\mathrm{pH}$ to climate variables along the climate gradient were explored through correlation and simple (multiple) linear regression analyses. The number of basic and derived climate (independent) variables was 3 to 4 times the number of dependent variables.
Considering these small sample sizes, the maximum number of independent variables in the multiple regression analyses was capped at three (using a start with one independent variable and stop with three variables selection and switching routine). Even with this restriction, however, several thousand candidate models were generated for each cultivar. Selection of the likely models for the given data among these candidate models was carried out using Akaike Information Criterion corrected for small sample size (AICc) (Burnham and Anderson 2002). Of the candidates, the model with the minimum AICc and others within 5 units of the minimum AICc model were retained for further scrutiny of model results against some known biology of the attribute being modelled. For example, if a model relating anthocyanins levels to the duration of average temperature above $30^{\circ} \mathrm{C}$ during ripening had a positive sign (i.e. qualitatively different from what is experimentally determined) such a model would be excluded even if it had the minimum AICc. Model selection based on some of the more common criteria (e.g. adjusted $r^{2}$ and Mallows' $C_{\mathrm{p}}$ ) was carried out in addition to the information theory approach. The climate variables used for model building generally had high degrees of correlation. This often causes high multicollinearity, which is manifest, among others, in the form of high variance inflation factors (VIF) of parameter estimates and high condition numbers. Thus, the selected models were screened further with rule-of-thumb guidelines of 10 for VIF and 1,000 for condition number (Myers 1992). When a combination of climate variables

Table 2 Climate variables used for investigating grape fruit quality attributes at maturity

\begin{tabular}{|c|c|c|}
\hline Climate variable & Climate variables used previously & Additional variables used for this study \\
\hline \multirow[t]{6}{*}{ Temperature } & $\begin{array}{l}\text { Mean January temperature (Smart and Dry } 1980 \text {; } \\
\text { Webb et al. 2008a); Spring temperatures up to } \\
\text { flowering (Keller et al. 2010) }\end{array}$ & $\begin{array}{l}\text { October-February monthly minimum, maximum, and average } \\
\text { temperatures }\left({ }^{\circ} \mathrm{C}\right)\end{array}$ \\
\hline & $\begin{array}{l}\text { Growing season (GS) }{ }^{\mathrm{a}} \text { average temperature } \\
\quad \text { (Ashenfelter 2008; Jones et al. 2005) }\end{array}$ & GS minimum, average, and maximum temperatures \\
\hline & $\begin{array}{l}\text { Temperature during fruit maturity (Sadras et al. 2007a; } \\
\text { Storchmann 2005) }\end{array}$ & $\begin{array}{l}\text { Minimum, maximum, and average temperatures during ripening } \\
\text { period }^{\mathrm{b}}(\mathrm{RP}) \text {; Number of hours over } 25^{\circ} \mathrm{C} \text { during RP }\end{array}$ \\
\hline & $\begin{array}{l}\text { Degree days (sum of daily mean temperature over } \\
10^{\circ} \mathrm{C} \text { during GS) (Winkler 1974) }\end{array}$ & Growing degree days (GDD) during GS \\
\hline & $\begin{array}{l}\text { Number of days with maximum temperature over } \\
25^{\circ} \mathrm{C} \text { during GS (Jones and Davis 2000) }\end{array}$ & Number of days with maximum temperature over $25{ }^{\circ} \mathrm{C}$ during GS, and RP \\
\hline & $\begin{array}{l}\text { Diurnal range (DR) (Gladstones 1992; } \\
\text { Nemani et al. 2001) }\end{array}$ & $\begin{array}{l}\text { Monthly DR between December and February, GS, RP, veraison } \\
\text { to maturity period }{ }^{\mathrm{c}} \text {, and for the period between October and February }\end{array}$ \\
\hline \multirow{3}{*}{$\begin{array}{l}\text { Moisture } \\
\text { condition }\end{array}$} & Rainfall (mm) (Gladstones 1992) & Amount of rainfall for early (September-November) and for the whole GS \\
\hline & $\begin{array}{l}\text { Moisture stress (Chalmers et al. 2010; } \\
\text { Gladstones 1992) }\end{array}$ & $\begin{array}{l}\text { Daily mean evaporation between October and February months, and RP; } \\
\text { mean daily vapour pressure deficit (VPD) for October-February, } \\
\text { and for RP }\end{array}$ \\
\hline & $\begin{array}{l}\text { Soil water holding capacity (Jackson 2000; } \\
\text { Sivilotti et al. 2005) }\end{array}$ & Available soil water holding capacity in the top 2 A and B soil layers \\
\hline Radiation & Radiation (Ristic et al. 2007; Gladstones 1992) & Mean daily radiation between October and February, and for RP \\
\hline
\end{tabular}

${ }^{\mathrm{a}}$ Growing season: period between October and the date when the grapes reached $22^{\circ}$ Brix total soluble solids (TSS), i.e. common maturity

${ }^{\mathrm{b}}$ Ripening period: 30 days period preceding common maturity

${ }^{\mathrm{c}}$ The veraison to maturity period: period between the start of veraison and common maturity 
Table 3 October to March average temperature and rainfall across the study sites during Season 1 (2008-2009), and Season 2 (2009-2010). Data source: interpolated (Silo DataDrill) weather data (Jeffrey et al. 2001)

\begin{tabular}{llllll}
\hline Site & \multicolumn{2}{l}{$\begin{array}{l}\text { October-March average } \\
\text { temperature }\left({ }^{\circ} \mathrm{C}\right)\end{array}$} & & \multicolumn{2}{l}{$\begin{array}{l}\text { October-March rainfall } \\
(\mathrm{mm})\end{array}$} \\
\cline { 2 - 3 } \cline { 5 - 6 } \cline { 5 - 6 } & $2008-2009$ & $2009-2010$ & & $2008-2009$ & $2009-2010$ \\
\hline Chapman Valley & 23.1 & 24.2 & & 35 & 52 \\
Gin Gin & 21.5 & $--^{\mathrm{a}}$ & & 96 & - \\
Swan Valley & 21.9 & 23.2 & & 124 & 88 \\
Peel & 21.0 & 22.2 & & 161 & 78 \\
Capel & 19.6 & 20.5 & 94 & 65 \\
Wilyabrup & 18.7 & 19.1 & & 161 & 95 \\
Rosa Brook & 18.2 & 18.9 & & 140 & 96 \\
Kudardup & 18.1 & 18.6 & 239 & 95 \\
Frankland & 17.9 & - & 219 & - \\
Pemberton & 17.7 & 18.8 & 363 & 154 \\
\hline
\end{tabular}

${ }^{\mathrm{a}}$ Sampling was not done at those vineyards

appeared to account for a very high proportion of the observed variance in berry trait (e.g. $>97 \%$ for $\mathrm{pH}$ ) while exhibiting severe multicollinearity, ridge regression was performed on such variables. However, it was often the case that, at the ridge step that stabilised parameter estimates (VIF $\sim 1)$, the penalised ridge model no longer retained its high explanatory power. In such cases, the variables and/or models were excluded from the results presented here despite the apparently high descriptive power of the initial models. Finally, for the data under consideration, one to three most probable models were presented and discussed for each attribute per cultivar (cultivar-specific models) or each attribute across cultivars (generic models).

The predictive performances of the selected models were evaluated using the leave-one-out cross validation (LOOCV) procedure as in Efron and Gong (1983) and Williams et al. (2005). In this procedure, each observation is left out one at a time and its value predicted using a new model parameterised on the remaining $n-1$ observations. Thus, for a sample of size $n, n$ sets of models are generated (on $n-1$ observations) to predict the corresponding left out observations. The average LOOCV prediction error estimate is (Efron and Gong 1983):

$\frac{1}{n} \sum_{l=1}^{n}\left(y_{l}-\widehat{y}_{l}\right)^{2}$

where $n$ is the sample size or the number of validations, $y_{1}$ is the left out observation and $\widehat{y}_{l}$ is its predicted value. All analyses were carried out with SAS v 9.1 (SAS Institute, Cary, NC).

\section{Results}

Patterns of total anthocyanins, TA and $\mathrm{pH}$ at common maturity across sites

At common maturity, there were significant differences in berry composition between the cooler and warmer sites. Generally, berries from the cooler sites, for instance Frankland and Pemberton, had higher levels of anthocyanins (48-71 \% for Cabernet Sauvignon and 22-30 \% for Shiraz, depending on the season) than those from the warmer sites, such as the Swan or the Chapman Valleys (Fig. 2). Likewise, the levels of TA were higher in the cooler than in the warmer sites: $31-62 \%$ for Cabernet Sauvignon, 32-82 \% for Shiraz, and $61-126 \%$ for Chardonnay depending on season (Fig. 2). Unlike the anthocyanins and TA levels, berry juice $\mathrm{pH}$ at common maturity did not show a clear trend across sites when the sites were characterized by the long-term growing season average temperature alone (Fig. 2). Nonetheless, the highest juice $\mathrm{pH}$ levels were observed at the warmer sites in both seasons (Chapman Valley for Shiraz and Cabernet Sauvignon, and at the Swan Valley for Chardonnay).

Relationships of total anthocyanins, TA and $\mathrm{pH}$ with climate variables

Exploratory bivariate correlation analyses of climate variables at different periods during the growing season and berry components at common maturity identified climate variables and critical periods that were influential on berry composition.

Rainfall, either early in the growing season (SeptemberNovember) or during the entire growing season, had positive impacts on TA levels at common maturity (Fig. 3a). Available soil water holding capacity (AWC) generally had little influence on TA at common maturity. By contrast, for all three ccultivars, TA levels at common maturity were negatively related to temperature (and temperature-derived variables), radiation and evaporation (Fig. 3a). In particular, consistently moderate to strong negative correlations $(-0.82$ to -0.47$)$ were observed with variables involving maximum temperature and its derivatives such as diurnal temperature ranges and vapour pressure deficit (VPD) during December, January and February; frequency of days above $25^{\circ} \mathrm{C}$ during the growing season, and the number of hours over $30{ }^{\circ} \mathrm{C}$ during the ripening period (Fig. 3a). Correlations of TA with minimum temperatures early in the growing season were both weak and varied among cultivars; however, the strength of correlations increased steadily and became qualitatively similar as the season progressed, becoming strongest during the ripening period (Fig. 3a). Such steady increases in the correlation strength from October to January/February months were also evident for the other monthly average climate variables (Fig. 3a). 
Fig. 2 Levels of grape quality attributes [anthocyanins, titratable acidity (TA), and $\mathrm{pH}]$ at total soluble solids (TSS) of $22^{\circ}$ Brix. Sites are listed (from left to right) according to their long-term growing season temperature in decreasing order

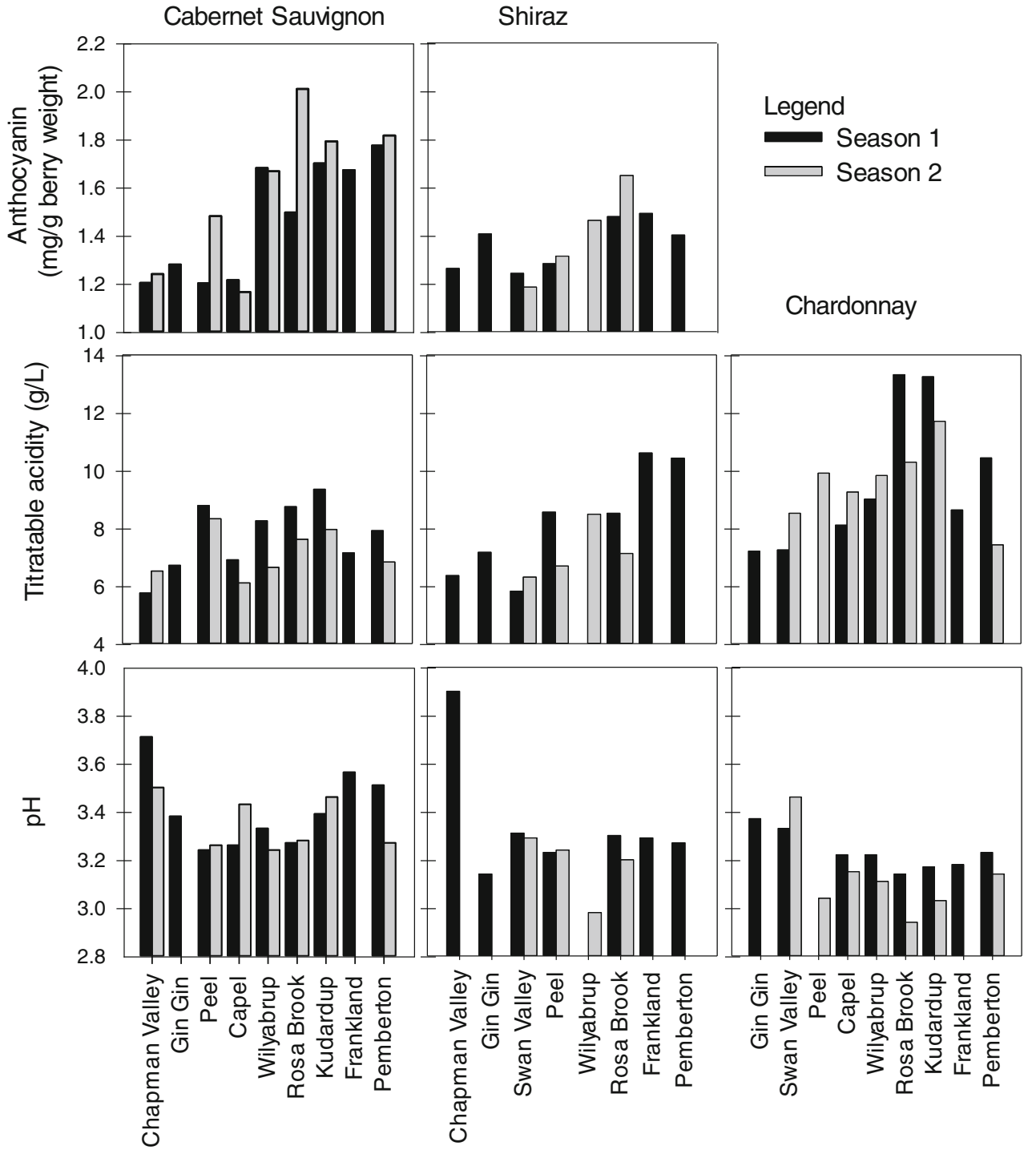

The correlations of juice $\mathrm{pH}$ with all climate variables were: (1) opposite to the TA results, and (2) of generally lower strength than the TA correlaions with the same variables (cf. Fig. $3 \mathrm{a}$ and $\mathrm{b}$ ). While the strongest $\mathrm{pH}$ correlations were observed with climate variables for the month of February and, unexpectedly, October (Fig. 3b), the correlations showed dynamic temporal patterns. Thus, in general, $\mathrm{pH}$ correlations with temperature, diurnal range and VPD variables started with a peak in October, attained a minimum in November and rose steadily back to peak level in February; correlations with evaporation and radiation variables also started with a peak in October, declined until December and returned to a peak level in February (Fig. 3b).

For both Shiraz and Cabernet Sauvignon, berry anthocyanins concentrations were associated negatively with almost all the climate variables examined in this study (Fig. 3c). Only rainfall variables had positive influences. Rainfall incident early in the growing season (September-November) appeared to have a stronger influence on berry anthocyanins than rainfall during the whole growing season. Similar to the results for $\mathrm{pH}$, berry anthocyanins concentrations of both red cultivars were highly negatively correlated $(-0.83<r<-0.77)$ with October temperatures, particularly the average and maximum temperatures (Fig. 3c). The strengths of correlations with November temperatures showed a slight drop, from there on however, the influences of temperatures on berry anthocyanins concentration increased steadily up to January/February (Fig. 3c). This temporal pattern was common across the minimum, average and maximum temperatures. Similarly, the degree of association between berry anthocyanins concentration at common maturity with diurnal range variables, while generally moderate during December $(-0.4<r<-0.2)$, became stronger $(-0.75<r<-0.50)$ towards the ripening period. Other variables that appeared to exert a relatively strong negative influence $(r<-0.7)$ on berry anthocyanins concentrations of both cultivars were the number of hours that the air 


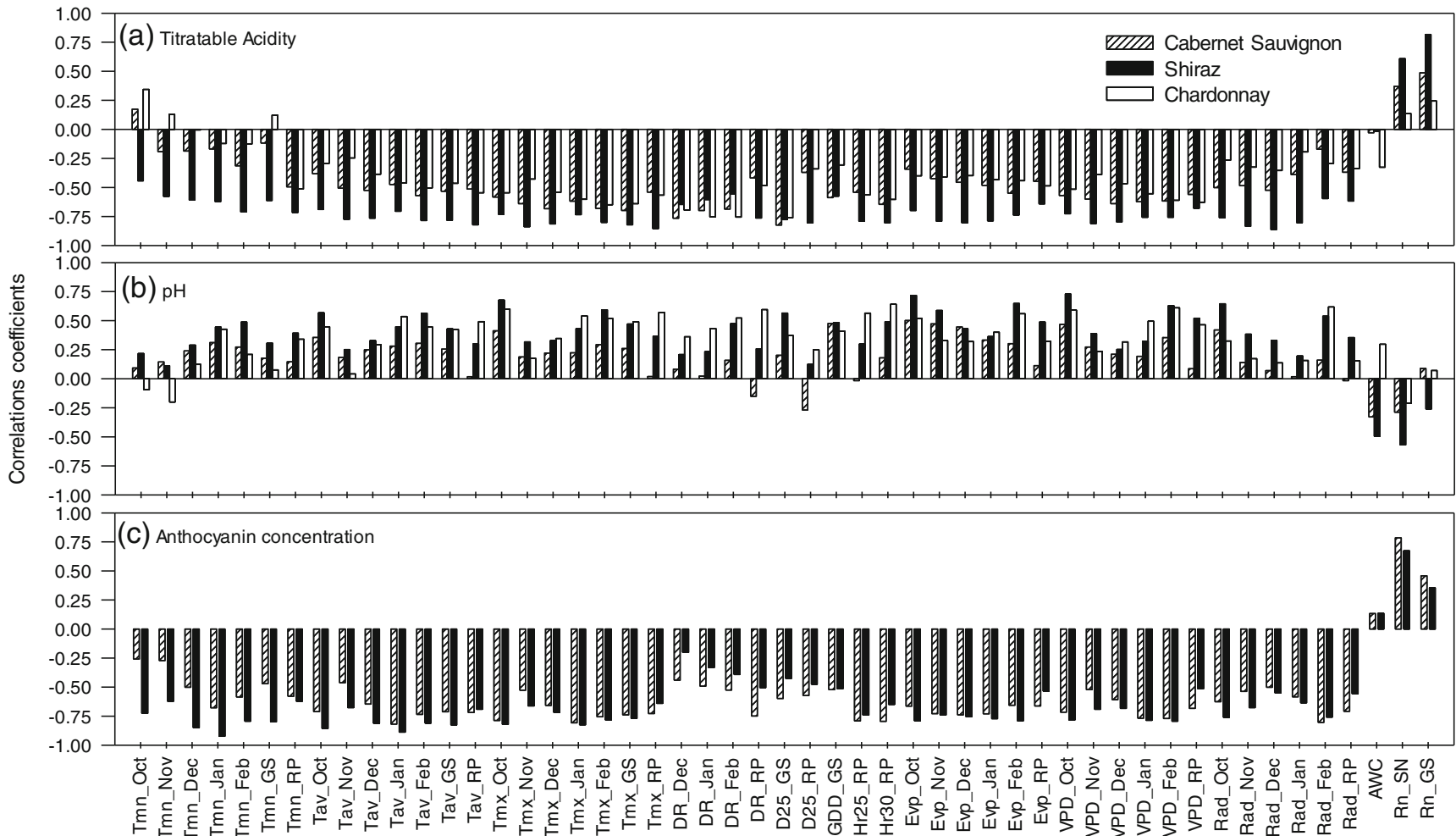

Fig. 3 Correlations between grape quality attributes (TA, pH and anthocyanin concentrations) at common maturity ( $22^{\circ}$ Brix TSS) and climate variables for Cabernet Sauvignon, Shiraz and Chardonnay. Months are denoted by their initial three letters. Tmn Minimum temperature; Tav average temperature; $\operatorname{Tm} x$ maximum temperatures; $R P$ ripening period; $D R$ diurnal range; $D 25, D 30$ number of days with maximum temperature

temperature exceeded $25^{\circ} \mathrm{C}$ during the ripening period, VPD during January/February and radiation in February. For most of the growing season, berry anthocyanins concentration also had a strong negative association with evaporative demand (Fig. 3c).

Temperature effects on rates of change of berry total anthocyanins, TA and $\mathrm{pH}$

For both red cultivars, berry anthocyanins concentrations were significantly and inversely related to the average temperature of the veraison to maturity period. However, the rate of decline, expressed as the slope of the linear regression, of anthocyanins concentrations per degree increase in the veraison to maturity period average temperature, was significantly greater for Cabernet Sauvignon (0.07) than for Shiraz (0.03) (Fig. 4). Similarly, for all three cultivars, the levels of TA declined significantly as a site's growing season average daily maximum temperature increased (Fig. 5a). The rate of acid loss, however, varied with cultivar, with Cabernet Sauvignon and Chardonnay being the least and most sensitive, respectively (Fig. 5a). In contrast to the responses of anthocyanins and TA, $\mathrm{pH}$ levels for all cultivars showed consistent over $25^{\circ} \mathrm{C}$ or $30{ }^{\circ} \mathrm{C} ; \mathrm{H} 25, \mathrm{H30}$ number of hours over $25^{\circ} \mathrm{C}$ or $30{ }^{\circ} \mathrm{C}$; Evp Class A pan evaporation; VPD vapour pressure deficit; $R a d$ net radiation; $A W C$ available soil water holding capacity; $R n \_S N, R n \_G S$ rainfall during September to November or during growing season, respectively

positive trends with the growing season average daily maximum temperature, though these were not significant $(P>0.05)$ (Fig. 5b).

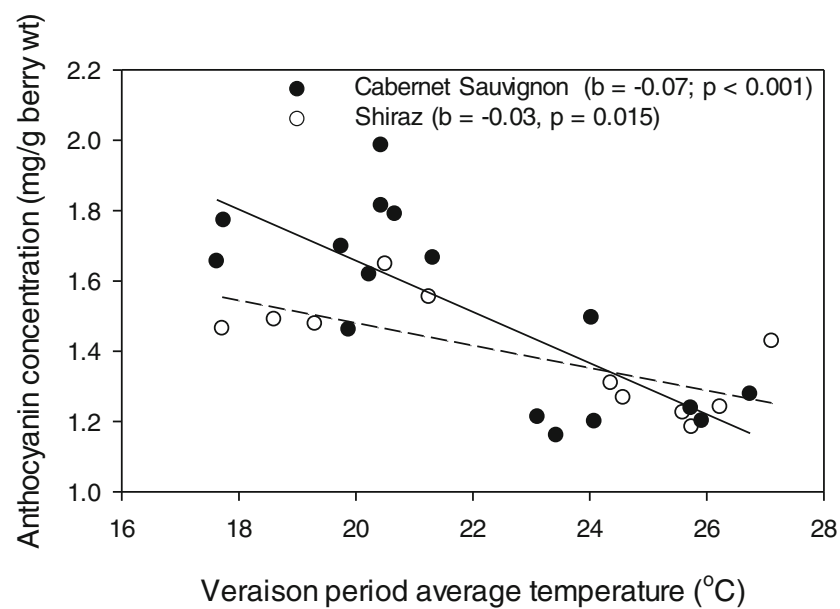

Fig. 4 Relationships between berry anthocyanin concentrations at 22 ${ }^{\circ}$ Brix TSS and the veraison period average temperature for Cabernet Sauvignon (filled circles) and Shiraz (open circles). Data points represent different sites. $b$ Slope of the regression line, $P$ probability of the trend line being different from zero 
Fig. 5 Relationships between berry $\mathbf{a} \mathrm{TA}, \mathbf{b} \mathrm{pH}$ and the growing season maximum temperature for Cabernet Sauvignon (filled circles), Shiraz (open circles) and Chardonnay (triangles). Data points represent sites. $b$ Slope of the regression, $P$ probability of the trend line being different from zero

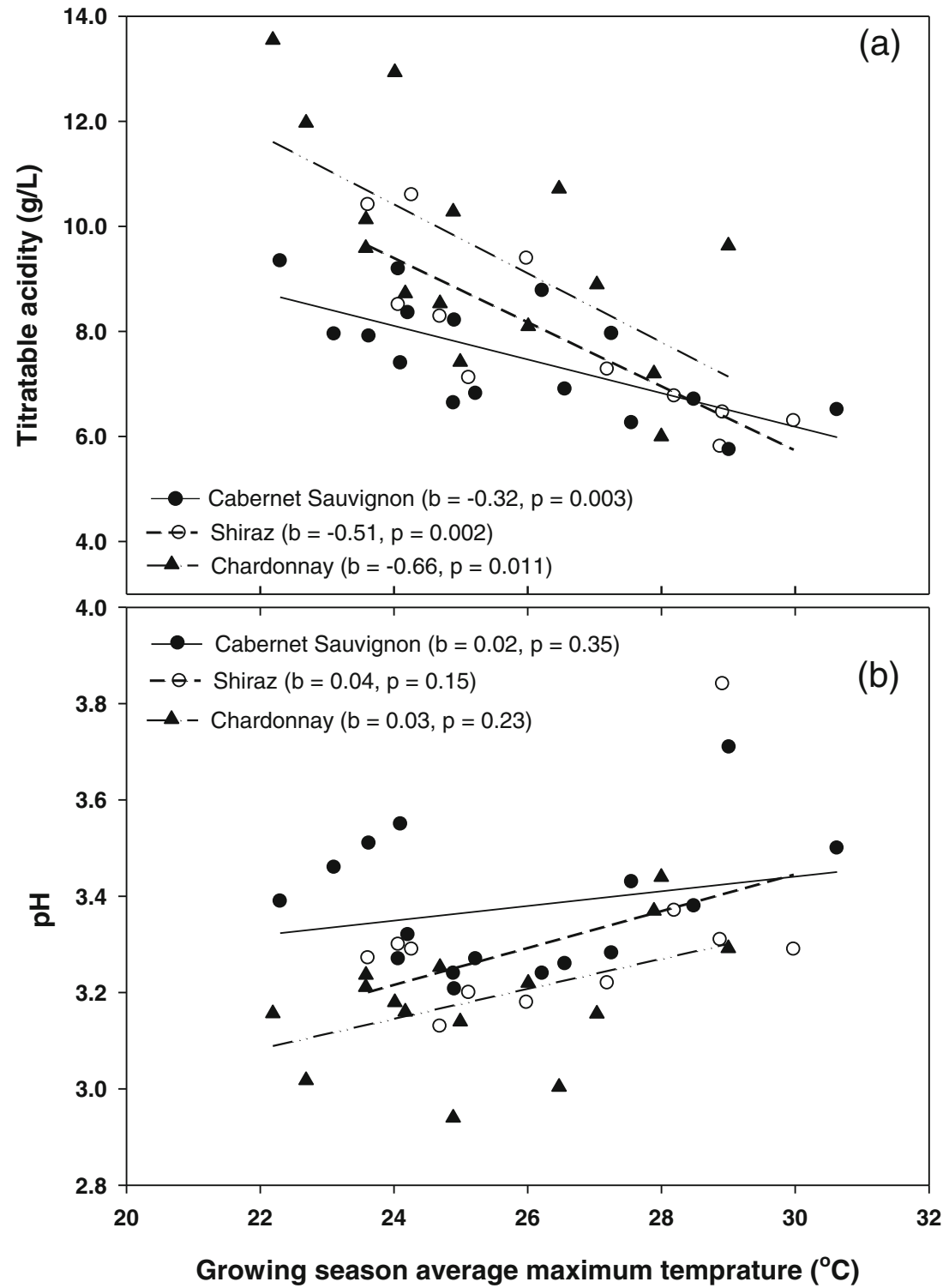

Empirical models for total anthocyanins, TA and $\mathrm{pH}$ responses to changing climate conditions

Out of more than 70 basic and derived climate variables, only a few (mean January temperature, radiation and number of hours over $25^{\circ} \mathrm{C}$ during the berry ripening period, and rainfall both during the September-November period, and the whole growing season) were pertinent for describing the variations in berry anthocyanins concentration along the $700 \mathrm{~km}$ sampling transect covering all major viticultural regions of Western Australia (Table 4).

A three-variable generic model consisting of rainfall during spring, the growing season and the number of hours that the air temperature exceeded $25{ }^{\circ} \mathrm{C}$ during the berry ripening period explained $>70 \%$ of the variation in berry anthocyanins concentrations for both cultivars (Table 4). The effects of these 
Fig. 6 Relationships between the veraison period average temperature and rates of change in a TA, b anthocyanin concentration per unit of TSS increase for Cabernet Sauvignon (circles), Shiraz (squares) and extreme values of (filled circles) Cabernet Sauvignon TA were not included in the regression. Inset Estimation of the rates of change of quality attributes over the veraison to harvest period using the sequential sampling data for the Kudardup site in Season 2 Chardonnay (triangles). Two

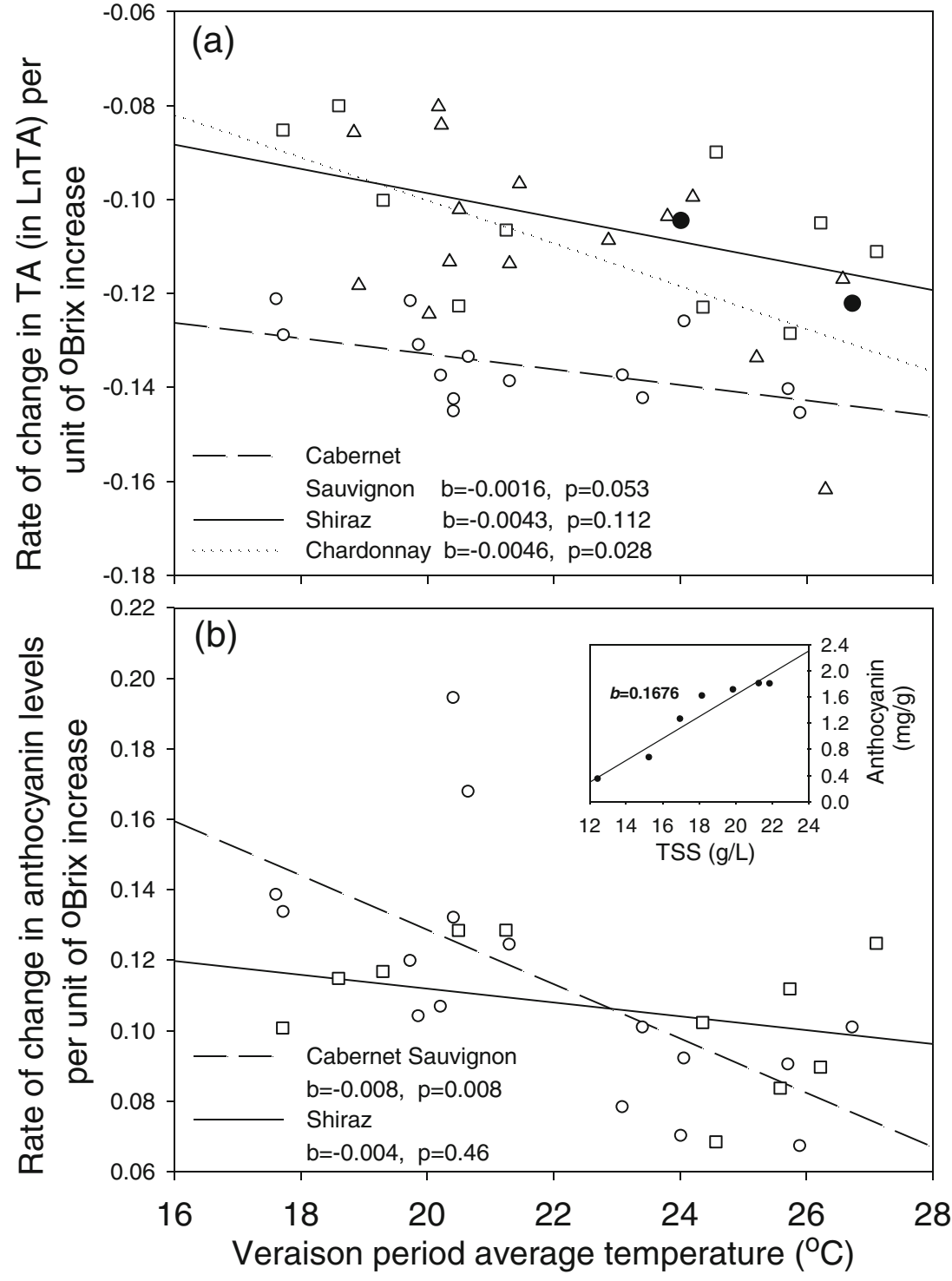

three variables on berry anthocyanins were in the same direction as their individual effects (cf. Fig. 3c, Table 4). The effects of rainfall, however, were dependent on when it occurred during the growing season. Whilst rainfall early in the growing season (September-November) had a positive effect, rainfall over the entire growing season had an unfavourable effect on berry anthocyanins levels. Partitioning the total growing season rainfall into early and late season rainfall also produced qualitatively and quantitatively comparable effects (data not shown).

Compared to the generic model result, high proportions of the variations in berry anthocyanins were accounted for by cultivar-specific models. For Cabernet Sauvignon, the same three variables used in the generic model explained $83 \%$ of the variability in berry anthocyanins concentrations across the sampling transect (Table 4). For Shiraz, a two-variable model of January minimum temperature and ripening period radiation described $70 \%$ of the variation across sites. However, when one highly influential outlier observation was excluded, the proportion of variance explained by the same two variables increased to $94 \%$ (Table 4). It is noteworthy that, for both cultivars, when a model contained both temperature and ripening period radiation, the radiation effect on anthocyanins concentrations was positive (i.e., contrary to the bivariate effect). Also notable was that, for both cultivars, the minimum or average January temperature alone accounted for between $50 \%$ and $83 \%$ of the variablity in berry anthocyanins concentrations (Table 4). Although not tabulated, for Shiraz-a cultivar known for its propensity for berry shrivel-berry anthocyanins concentrations responded significantly and positively to VPD. (For example: anthocyanins ${ }_{\text {(Shiraz) }}=3.78+$ 0.0354 November VPD +0.0233 ripening period VPD - 0.1406 January to February mean temperature, $r^{2}$ adj= 0.92 ; anthocyanins (Shiraz) $=3.44+0.023$ December VPD+ ature, $r^{2}$ adj=0.89; all terms significant at $P<0.001$ ). 0.0162 ripening period VPD -0.1187 mean January temper- 
Table 4 Generic and variety-specific model estimates for berry anthocyanin concentration $\left(\mathrm{mg} / \mathrm{g}\right.$ berry) $V I F_{\max }$ Maximum variance inflation factor, $R n S N, R n G S$ September to November months and GS rainfalls (mm), $H r 25 R P$ number of hours over $25^{\circ} \mathrm{C}$ during ripening period, Tav_Jan, Tmn_Jan average and mean of minimum temperatures in January $\left({ }^{\circ} \mathrm{C}\right), \operatorname{Ra} d \_R P$ radiation during ripening period $\left(\mathrm{MJ} / \mathrm{m}^{2}\right)$

\begin{tabular}{|c|c|c|c|c|c|c|c|c|c|c|}
\hline \multirow[t]{2}{*}{ Variety } & \multirow[t]{2}{*}{ Intercept } & \multicolumn{6}{|c|}{ Climate variables } & \multicolumn{3}{|c|}{ Model performance } \\
\hline & & $\mathrm{Rn} \_\mathrm{SN}$ & Rn_GS & Hr25_RP & Tav_Jan & Tmn_Jan & Rad_RP & Adj_ $r^{2}$ & $\mathrm{PE}^{\mathrm{a}}$ & $\mathrm{VIF}_{\text {max }}$ \\
\hline Generic model & $1.68 * * *$ & $0.00196 * * *$ & $-0.0019 * * *$ & $-0.0014 * * *$ & & & & 0.72 & 0.13 & 3.06 \\
\hline \multirow[t]{2}{*}{ Cabernet Sauvignon } & $1.72 * * *$ & $0.00229 * * *$ & $-0.00200 * * *$ & $-0.00172 * * *$ & & & & 0.83 & 0.12 & 2.83 \\
\hline & $3.63 * * *$ & & & & $-0.094 * *$ & & & 0.65 & 0.17 & - \\
\hline \multirow[t]{4}{*}{ Shiraz } & $2.39 * * * \mathrm{~b}$ & & & & $-0.042 * *$ & & & 0.50 & 0.12 & - \\
\hline & $2.38 * * * \mathrm{c}$ & & & & & $-0.091 * * *$ & $0.022 * *$ & 0.94 & 0.04 & 2.89 \\
\hline & $2.40 * * * \mathrm{c}$ & & & & & $-0.061 * * *$ & & 0.83 & 0.07 & - \\
\hline & $2.59 * * * \mathrm{c}$ & & & & $-0.051 * * *$ & & & 0.77 & 0.08 & - \\
\hline
\end{tabular}

** $P<0.01, * * * P<0.001$

${ }^{a}$ Square root of average prediction error (PE) (i.e. in original measurements unit)

${ }^{\mathrm{b}}$ Based on all data

${ }^{\mathrm{c}}$ Excludes one outlier observation

\section{Juice $\mathrm{pH}$}

Compared to anthocyanins and TA (see below), juice $\mathrm{pH}$ at common maturity was generally weakly associated with the climate variables examined in this study. Yet, several models appeared to describe high proportions (e.g. up to $97 \%$ for Shiraz) of the variances in $\mathrm{pH}$ along the sampling transect. However, the parameter estimates for one or more of the variables in the models were unreliable and all such models were excluded. After this screening, the "best" candidate was a generic model, containing growing season degree days and October VPD, which described only half of the $\mathrm{pH}$ variations along the climate gradient (Table 5). For both variables, the directions of influence on $\mathrm{pH}$ were same as their individual effects.

\section{Titratable acidity}

For all cultivars, between $59 \%$ and $63 \%$ of the variations in berry TA levels were described using generic models consisting of two temperature derived-variables: (1) growing season diurnal range (DR_GS) and ripening period minimum temperature (Tmn_RP), (2) growing season degree days (GDD_GS) and January diurnal range or (3) GDD_GS and

Table 5 Generic model estimates for $\mathrm{pH}$ level. GDD_GS growing season degree days, VPD_Oct October mean daily vapour pressure (hPa). See Table 4 for definitions

\begin{tabular}{lllllll}
\hline Intercept & \multicolumn{2}{l}{ Climate variables } & & \multicolumn{3}{l}{ Model performance } \\
\cline { 2 - 3 } \cline { 5 - 7 } & GDD_GS & VPD_Oct & & Adj_r ${ }^{2}$ & PE & VIFmax \\
\hline $2.06^{* * *}$ & $0.00071^{* * *}$ & $0.021^{* * *}$ & & 0.52 & 0.13 & 1.31 \\
\hline
\end{tabular}

** $P<0.01, * * * P<0.001$
October to February diurnal range (Table 6). In all three generic models, the impacts of these temperature derivatives on TA were significant $(P<0.001)$ and negative (Table 6$)$.

As observed for the total anthocyanins, cultivar-specific TA models explained significantly higher proportions of the variation in TA than were possible with the generic models (Table 6). For Cabernet Sauvignon, a model containing DR_GS and Tmn_RP accounted for about $77 \%$ of the variability in TA, while a three-variable model with GDD_GS, DR_GS and Rn_GS (growing season rainfall) explained $85 \%$ of the TA variation at maturity along the climate gradient. Once more, the impacts of the temperature variables were negative whilst that of rainfall was positive.

For Chardonnay, the conjoint influences of DR_GS and Tmn_RP alone explained $81 \%$ of the TA variance at maturity. Two three-variable models: (1) DR_Feb (February diurnal range), Tmn_RP, Rad_Oct (October radiation) and (2) Tmn_RP, D25_GS (days with maximum temperature over $25{ }^{\circ} \mathrm{C}$ during growing season) and Rad_Nov (November radiation) accounted for slightly more of the variances across the climate gradient (Table 6). As observed for Cabernet Sauvignon, the effects of all the temperature-derived variables on TA were negative.

For Shiraz, the maximum temperature during the ripening period alone explained $70 \%$ of the variation in TA at common maturity across the sampling transect. However, the best candidate model contained two variables (October to February diurnal range and Rn_GS), which jointly accounted for $82 \%$ of the variation in Shiraz TA across the transect over two seasons. Similar to the results for Chardonnay and Cabernet Sauvignon, the effects on TA of the temperaturebased factors in the Shiraz models were negative while the impact of rainfall was positive (Table 6). 


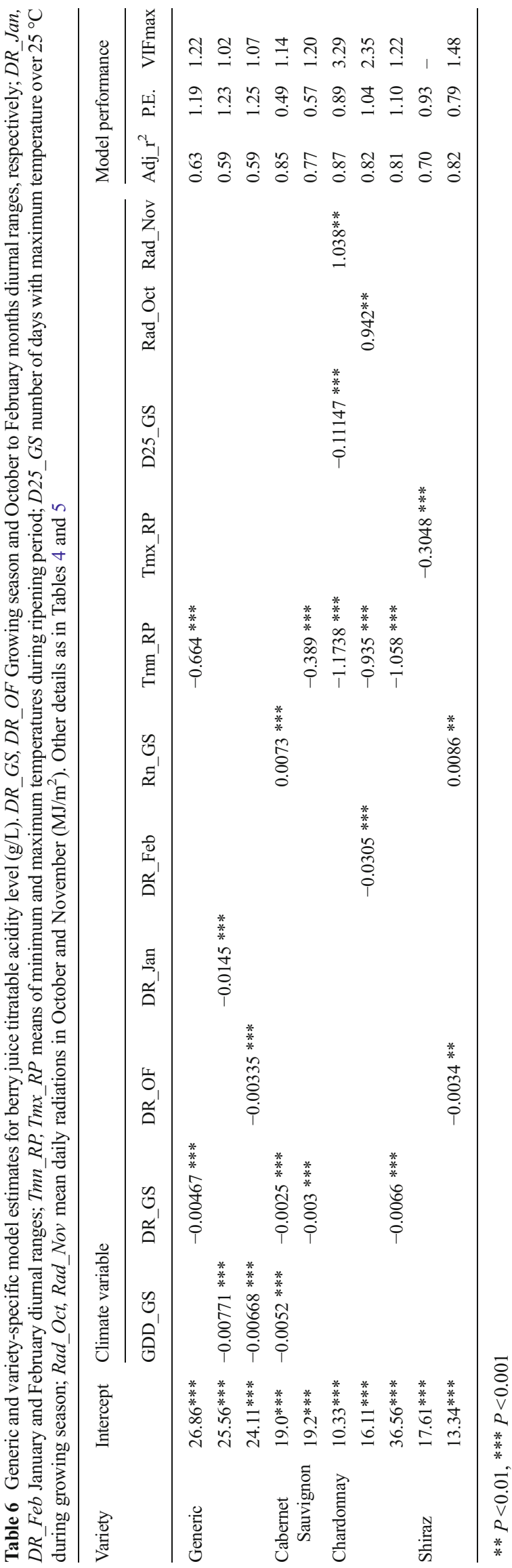

Model evaluation

Cross-validation analysis results of the prediction errors for the selected models are shown in Tables 4-6. Comparing between the berry attributes, the relative prediction errors were lower for anthocyanins than for TA. In terms of model types, the predictive abilities of the generic models were, on the whole, lower than those of the cultivar-specific models. Nonetheless, for the data ranges observed in the current study, the prediction errors (when expressed as root-mean-square of prediction errors relative to the observed mean of a berry attribute) were less than $17 \%$ for anthocyanins and TA across all cultivars.

\section{Discussion}

This work aimed to investigate the influences of climate variables (using a climate gradient) on berry TA, anthocyanins and $\mathrm{pH}$ for three major winegrape cultivars, and to develop empirical climate-variable based empirical models that describe the observed responses. Weekly berry sampling along a 700-km transect covering all the Western Australian wine growing regions provided the relevant berry composition data and climate-gradient to address these aims. Such a long sampling transect is also likely to generate "gradients" in variables other than climate (e.g. soil type, management). Nonetheless, when the results were examined at a standardised berry maturity: (1) there were clear differences, particularly in berry anthocyanins concentration, TA and to a lesser extent in $\mathrm{pH}$, along the transect; and (2) more significantly, most of the variations in these berry components along the transect were accounted for using variations in the prevailing climates of the sites. As such, this provides a clear indication that (1) macroclimate exerts a dominant influence in shaping the regional pattern of berry composition (Smart 1985; Winkler 1974), and (2) the information so gleaned may, with caution, be used for assessing impacts of climate change on berry composition. Details are discussed in the following sections.

Acidity along the climate gradient

For all three cultivars, bivariate correlation analyses of TA at maturity with climate variables have discerned at least three salient features: (1) TA is correlated negatively with almost all monthly climate variable indices throughout the growing season except rainfall, (2) by contrast, the TA correlations with rainfall variables are positive, and (3) the strength of the associations (regardless of its sign) between TA and climate variables increases steadily from early growing season towards the berry ripening period, indicating that the ripening period climate is more influential in determining berry composition at maturity (Buttrose et al. 1971; de Orduna 2010; 
Jackson and Lombard 1993). In particular, across cultivars, some of the strongest and most consistent negative associations of TA were with maximum temperatures. This may reflect the observation that, in berries, tartaric and malic acids constitute most (up to $92 \%$ ) of the total TA (Kliewer 1966) and that respiration of berry acids, particularly malic acid, increases with increasing temperatures (Coombe 1987; Sweetman et al. 2009). As indicated above, only rainfall variables were found to have positive influence on TA levels at maturity. The precise mechanism of how rainfall favours high TA levels is not clear, but possibilities include indirect influences via (1) lowering of air temperature with an increase in rainfall, and (2) increased vegetative growth with increased moisture availability-both of which would favour TA levels.

$\mathrm{pH}$ trend along the climate gradient

The associations between $\mathrm{pH}$ and monthly or ripening period temperature variables were generally positive. Dry (1983), using a broadly similar approach, also found a positive relationship between Shiraz berry $\mathrm{pH}$ and January average temperatures. Considerable increases in berry $\mathrm{pH}$ occur during berry ripening (Winkler 1974). However, influences of ripening period temperatures on $\mathrm{pH}$ were relatively modest for the red cultivars, particularly in Cabernet Sauvignon.

Influences of moisture-related variables (rainfall and available soil water holding capacity) on berry $\mathrm{pH}$ levels, apart from being moderate, were also inconsistent among cultivars. All sites applied different levels of supplementary irrigation during the later periods of the growing season and therefore may have contributed to the lack of consistency of the moisture-related variables' effects on $\mathrm{pH}$ levels at maturity. According to Smart (1985), of the three berry attributes examined here, berry $\mathrm{pH}$ is the most sensitive to climate conditions within a vine canopy (microclimate). The within-vine microclimate can vary considerably within a field as a function of canopy size. It is thus probable that microclimate variations may have masked the macroclimate influence on $\mathrm{pH}$, and hence the "lack" of a strong $\mathrm{pH}$ trend along the climate gradient.

Trend of total anthocyanins along the climate gradient

Accumulation of anthocyanins commences at veraison for red grape cultivars (Mullins et al. 1992) and the accumulation process is influenced by environmental and management conditions (Downey et al. 2006; Kliewer and Weaver 1971). It was, thus, anticipated that anthocyanins levels would show a strong association with ripening period climate variables. This was generally borne out in that some of the strongest (negative) correlations were with climate variables from January and February (months which make up part of the ripening period). More generally, for both red cultivars, higher berry anthocyanins concentrations were found in berries from cooler rather than from warmer sites, consistent with earlier reports (Kliewer and Torres 1972; Kliewer 1977; Mori et al. 2005).

For Cabernet Sauvignon, strong negative associations between anthocyanins levels at maturity and January average or maximum temperature, or duration of hours $>25^{\circ} \mathrm{C}$ or $>$ $30{ }^{\circ} \mathrm{C}$ during the ripening period were observed. Surprisingly, these results from the $700-\mathrm{km}$ long climate gradient study are remarkably consistent with the results of Mori et al. (2007) from a controlled environment study that demonstrated striking effects of high daytime temperature $\left(35^{\circ} \mathrm{C}\right)$, which caused a more than $50 \%$ reduction in Cabernet Sauvignon anthocyanins accumulation compared to the control treatment $\left(25^{\circ} \mathrm{C}\right.$ daytime temperature). Net anthocyanins accumulation is a balance between synthesis and degradation, and, according to Mori et al. (2007), low levels of anthocyanins, at least in Cabernet Sauvignon, under high temperature conditions result primarily from increased degradation and secondarily from reduced synthesis.

For Shiraz anthocyanins, the average minimum temperature in January emerged as the most influential variable. As reviewed by Jackson and Lombard (1993), berry anthocyanins are reduced or enhanced above or below a night-time temperature of $15{ }^{\circ} \mathrm{C}$, respectively. For the majority of the sites in this study, the average night-time temperature was over $15^{\circ} \mathrm{C}$ in January, and therefore minimum temperature may have exerted more influence on Shiraz anthocyanins concentration than the other climate variables. In this regard, it is worth noting that climate projections indicate a relatively greater rise in the minimum temperature, during the ripening period.

The degree of association between berry anthocyanins concentration at maturity and the maximum temperatures in October and January were similar. As such, this is contrary to the expectation that anthocyanins accumulation is more influenced by the ripening period climate than by climatic events prevailing at the start of the growing season. Indeed, other climate indices for the month of October also showed a consistently moderate to strong influence on (correlation with) the berry attributes examined in this study. One possible explanation is that warmer temperatures early in the growing season shorten the season (Coombe 1988) and thereby bring forward the ripening to the warmer period, which is detrimental for anthocyanins accumulation in berries as discussed above. The strong inverse relationships between the maximum temperature in October and the dates of maturity for all three cultivars (data not shown) support this contention. A further possibility is that warmer events early in the spring (while soil moisture is still high) favour increased vegetative growth which often tends to lessen anthocyanins concentrations (Smart et al. 1988). 
Of all the correlations between the anthocyanins levels and climate variables, only those with the water-related variables (available soil water holding capacity, rainfall) had positive signs. And of these, only the correlations with rainfall in the September-November period were significant. While increased moisture availability late in the growing season is often reported to reduce anthocyanins levels (Chalmers et al. 2010; Jackson and Lombard 1993), it appears that improved water availability early in the growing season is beneficial as it promotes the initial and subsequent adequate vegetative growth (Keller et al. 2010) and, hence, proper development of the berry and its composition at later stages.

Temperature influence on rates of change of TA and total anthocyanins

TA levels at common maturity declined as the growing season average maximum temperature increased; however, the rates differed between cultivars. Similar responses have been indicated in other cultivars as a function of growing degree days (GDD; Winkler 1974). The magnitude of rate is, by definition, a reflection of the degree of each cultivar's TA variation. Thus Chardonnay, which showed the widest range of TA levels at common maturity, had the largest rate of drop $\left(0.66 \mathrm{~g} / \mathrm{L}\right.$ per ${ }^{\circ} \mathrm{C}$ warming in the growing season average maximum temperature), followed by Shiraz $(0.51 \mathrm{~g} / \mathrm{L})$; while Cabernet Sauvignon, which had the narrowest range of variation, dropped at half the rate of Chardonnay. These rates are inversely proportional to the cultivars' maturity grouping (Gladstones 1992). As such, at least for TA, these results are consistent with the view that the largest rate difference occurs between early- and late-maturing cultivars (Winkler 1974). These results also suggest that, other factors being the same, increased warming will have a relatively greater negative impact on Chardonnay TA than on Shiraz or Cabernet Sauvignon.

Similarly with TA, anthocyanins concentrations for both red cultivars were negatively related to (veraison to maturity period) temperature. However, unlike TA, anthocyanins concentration of Cabernet Sauvignon showed a wider range of variation across the temperature gradient than those of Shiraz. Consequently, the decline in anthocyanins with increasing temperature was higher for Cabernet than for Shiraz. This outcome suggests that the degree of plasticity of a trait in a given cultivar rather than a cultivar's maturity grouping determines the rate of change in a trait in response to temperature. Collectively, these contrasting results provide evidence for the differential influence of temperature not only among cultivars but also on different berry traits within a cultivar, and hence underscore a need for caution on extrapolating the impact of climate warming on other berry components and cultivars.
Temperature influence on rates of change in total anthocyanins and TA relative to sugar accumulation rates

The relative rates of change in berry components during ripening have crucial importance for viticulture since the ultimate composition of wine depends on the balance between sugar and the other elements of berry composition at harvest. In practice, TSS is used to assess berry ripeness with a tacit perception that accumulation rates of berry components are synchronous or closely coupled with soluble solids (but see Winkler 1974; Gladstones 1992). This study showed that for some combinations of cultivar and berry components (e.g. TA in Chardonnay and anthocyanins concentration in Cabernet Sauvignon) warmer ripening conditions significantly altered the rates of change of these attributes relative to soluble solids accumulation rates. Sadras et al. (2007b) also found a decoupling of anthocyanins and sugar accumulation rates in Cabernet Sauvignon with increasing water stress during the ripening period, although in this case anthocyanins were favoured. The relative accumulation rates shifted from nearly isometric in vines that received $50 \%$ more water than "standard" irrigation volume to increasingly allometric (in favour of anthocyanins) as irrigation volume declined to $40 \%$ of the "standard" level. These two lines of evidence show that heat and water stress elicit contrasting responses in anthocyanins accumulation rates relative to total soluble solids. In terms of the results observed from this study, the consequences of significant slowing of anthocyanins accumulation rates relative to the rates for soluble solids are manifested in reduced colouration of Cabernet Sauvignon berries under warmer ripening conditions (Fig. 3), although Shiraz appears relatively less sensitive. The decoupling of sugar and anthocyanins accumulation rates is understandably described in terms of the differential temperature optima of the respective processes (see Sadras et al. 2007b). The relative insensitivity of Shiraz suggests that, at least in this cultivar, the temperature optima ranges of processes responsible for sugar and anthocyanins accumulation are comparable. However, further evaluation whether this is the case is warranted.

Models for assessing responses of total anthocyanins, TA and $\mathrm{pH}$ to changing climate

For each of the three berry components examined here, it was possible to describe a significant proportion of their variation across the climate gradients using generic or cultivar-specific models (Tables 4-6). That it is possible to describe, albeit it to varying degrees, each berry attribute using a generic model suggests that, regardless of cultivar, a given berry attribute is influenced by a common underlying process, or that if different processes are at play these respond similarly to the same set of climate variables. Nonetheless, the descriptive performances of the generic models, except that of $\mathrm{pH}$, were 
generally lower than the cultivar-specific models, even when the climate variables were identical in both models. This, however, need not be unexpected considering that the three cultivars fall into three different maturity groups. That is, the critical berry development and/or ripening periods and the climate variables that prevail during the corresponding times are different for different cultivars. For this reason, the discussion that follows generally focusses on the cultivar-specific models.

The anthocyanin models were generally dominated by climate indices derived from part or whole of the anthocyanins accumulation period. The significant variables identified for describing anthocyanins concentration were temperature indices from the month of January and/or the ripening period, rainfall and radiation. The impacts of temperature variables (when present in the models alone or in combination with other climate variables) were negative, which is in accord with the widely understood effect of temperature on anthocyanins (see previous section). With respect to radiation, variable effects were observed depending on whether it was considered alone (Fig. 4) or together with temperature (Table 4). Reported effects of radiation on berry anthocyanins span the full spectrum of possible responses ranging from an increase (Kliewer 1977; Smart et al. 1988; Spayd et al. 2002), no effect (Cortell and Kennedy 2006; Downey et al. 2004) to a reduction (Haselgrove et al. 2000) in anthocyanins concentrations as radiation levels increase. The diversity of reported responses is likely to reflect differences in experimental set up with variable control in temperature (Downey et al. 2004). However, even when temperature is carefully controlled, variable though qualitatively similar responses to radiation are reported, from an increase (Spayd et al. 2002) to no effect (Cortell and Kennedy 2006; Downey et al. 2004). However, from multiple regression analyses (Table 4) it emerged that when radiation and temperature from the ripening period occurred together in anthocyanins models, the radiation effect was positive while temperature was consistently negative. This approach appears to be useful in differentiating the effects of temperature and radiation on berry anthocyanins levels, and supports the suggestion that the apparent negative effect of radiation is a reflection of the attendant elevated temperature load effect (Bergqvist et al. 2001; Downey et al. 2004; Haselgrove et al. 2000).

$\mathrm{pH}$ was the most recalcitrant of the berry attributes to describe adequately in terms of macroclimate variations along the climate gradient. Only about half the variations in $\mathrm{pH}$ could be described by a generic model containing GDD and October VPD. The influences of both variables on $\mathrm{pH}$ were positive (same as in the bivariate analyses). Boulton (1980) has shown that berry $\mathrm{pH}$ is primarily a function of the levels of organic acids and the monovalent cations, mainly potassium. It can thus be argued that to the extent climate influences $\mathrm{pH}$, the effect is indirect via the levels of acids and cation uptake.
In this respect, the positive influence of high GDD is likely to relate to its negative impact on acidity (Winkler 1974; this study) which, other things being equal, elevates berry $\mathrm{pH}$. On the other hand, how VPD in October positively influences berry $\mathrm{pH}$ is less clear. However, high VPD early in the growing season (October), when soil moisture is relatively adequate, promotes water and potassium uptake (Rankine et al. 1971; Ruhl 1992) and sequestration in the vine system. Part of the potassium so sequestered is remobilised during ripening to augment the potassium levels in berries (Conradie 1981), which may then contribute positively to berry $\mathrm{pH}$ (Boulton 1980; Rankine et al. 1971).

Across all three cultivars, a high proportion of the variation in TA along the climate gradient was accounted for. The most pertinent variables for describing TA variations along the climate gradient were primarily temperature and temperaturederived variables, and growing season rainfall. The joint influences of these temperature and rainfall variables on TA were directionally the same as the individual effects. While the negative effect of maximum temperature on TA is well acknowledged, an outstanding observation from this gradient study is the prevalence of the ripening period minimum temperature in the TA models of all three cultivars. Further, the impact of this variable on TA was without exception negative. Given that the minimum temperatures have increased faster than the maximum temperature (Easterling et al. 1997), increased acid loss may occur even without an increase in the maximum temperature.

Prediction errors of the final models, although the validation was based on a relatively small dataset, were within $17 \%$ of the means regardless of cultivar or berry attributes. While this level of prediction error may be considered acceptable, there were cultivar-, model- (generic vs cultivar-specific), and berry attribute-dependent differences in the magnitude of prediction errors. These differences appear to be linked to the degree of variation in a trait's value at common maturity: the greater the spread in a given trait's value at common maturity, the greater the error of prediction. This is more clearly seen with regard to TA (cf. Table 6, Fig. 2).

Although the models presented here accounted for a high proportion of the variation in the berry attributes examined for all three cultivars, caution is advised when applying these models in other environments. As with any other regression models, these empirical models are not free of shortcomings since these were not based on mechanistic processes, although known effects on the (direction of) impact of specific climate variables on berry composition were taken into account in the model selection process. Further, non-climatic factors (such as crop load, canopy manipulation, soil management), which can influence berry composition (Kliewer and Weaver 1971; Smart 1985; Jackson and Lombard 1993), were not explicitly incorporated. Additionally, in this study, climate variables whose 
values are functions of time, such as GDD, were used. On the other hand, levels of the berry components are also time dependent. Hence, it is possible that regression between such time dependent variables yields fortuitous associations (sensu Jones and Davis 2000). However, the berry components examined for this study were not dependent on elapsed time since these were standardised to a common maturity TSS $\left(22^{\circ} \mathrm{Brix}\right)$ across sites. Therefore, it is argued that even though some time dependent variables are included in the models, the results are unlikely to be coincidental, and the inferences drawn from the models are valid.

\section{Conclusion}

This study has shown that, for all three major winegrape cultivars examined here, there were strong trends in berry anthocyanins concentrations and titratable acidity along the $700-\mathrm{km}$ transect (climate gradient). This demonstrates that, despite variations in a range of factors that can potentially affect berry composition, climate is the dominant factor in shaping the regional pattern of berry composition. This provides support for the use of climate gradient as a surrogate for evaluating potential impacts of changing climate on some aspects of viticulture. These observations were used to develop parsimonious empirical models that, with consideration of the caveats discussed above, could be used for assessing climate change impacts on these berry attributes and cultivars across the wine regions of western Australia. While the key aspects of observations from the climate gradient are consistent with, and are underpinned by, results from controlled experiments, our results are nonetheless based on short-term (two seasons and ten regions) sampling. Thus, further observations (a longer time series) of climate and biochemistry data are warranted to both corroborate the conclusions of this short-term study and verify the robustness of model parameter estimates.

Acknowledgments The work reported here was supported by the CSIRO Climate Adaptation Flagship and the Grape and Wine Research and Development Commission postgraduate research grant to N.N.B. The authors thank vineyard owners and managers for allowing weekly fruit sampling from their properties as well as for providing information on vineyard management. Messrs B. Evans and D. Kelly are gratefully acknowledged for their assistance in sample collection and berry analyses, respectively. Ms V. Westwood kindly proofread the manuscript. The manuscript also benefited from the comments of editors and anonymous reviewers.

Open Access This article is distributed under the terms of the Creative Commons Attribution License which permits any use, distribution, and reproduction in any medium, provided the original author(s) and the source are credited.

\section{References}

Ashenfelter O (2008) Predicting the quality and prices of Bordeaux wine. Econ J 118:174-184

Bergqvist J, Dokoozlian N, Ebisuda N (2001) Sunlight exposure and temperature effects on berry growth and composition of Cabernet Sauvignon and Grenache in the Central San Joaquin Valley of California. Am J Enol Vitic 52:1-6

Boulton R (1980) The relationships between total acidity, titratable acidity and $\mathrm{pH}$ in grape tissue. Vitis 19:113-120

Burnham KP, Anderson DR (2002) Model selection and multimodel inference: a practical information-theoretic approach. Springer, New York

Buttrose M, Hale C, Kliewer W (1971) Effect of temperature on the composition of 'Cabernet Sauvignon' berries. Am J Enol Vitic 22:71-75

Chalmers Y, Downey M, Krstic M, Loveys B, Dry P (2010) Influence of sustained deficit irrigation on colour parameters of Cabernet Sauvignon and Shiraz microscale wine fermentations. Aust J Grape Wine Res 16:301-313

Conradie W (1981) Seasonal uptake of nutrients by Chenin Blanc in sand culture: II. Phosphorus, calcium and magnesium. S Afr J Enol Vitic $2: 7-13$

Coombe B (1987) Influence of temperature on composition and quality of grapes. Acta Hortic 206:23-35

Coombe B (1988) Grape phenology. In: Coombe B, Dry PR (eds) Viticulture. Volume 1-Resources. Winetitles, Adelaide, pp 139-153

Coombe B, Dundon R, Short A (1980) Indices of sugar-acidity as ripeness criteria for winegrapes. J Sci Food Agric 31:495-502

Cortell JM, Kennedy JA (2006) Effect of shading on accumulation of flavonoid compounds in (Vitis vinifera L.) Pinot Noir fruit and extraction in a model system. J Agric Food Chem 54:8510-8520

de Orduna M (2010) Climate change associated effects on grape and wine quality and production. Food Res Int 43:1844-1855

Downey MO, Harvey JS, Robinson SP (2004) The effect of bunch shading on berry development and flavonoid accumulation in Shiraz grapes. Aust J Grape Wine Res 10:55-73

Downey M, Dokoozlian N, Krstic M (2006) Cultural practice and environmental impacts on the flavonoid composition of grapes and wine: a review of recent research. Am J Enol Vitic 57:257-268

Dry P (1983) Recent advances in Australian viticulture. In: Lee TH, Somers TC (eds) Advances in viticuture and oenology for economic gain. Proceedings of the Fifth Australian Wine Industry Technical Conference, Perth. The Australian Wine Research Institute, Glen Osmond, SA, pp 9-21

Easterling DR, Horton B, Jones PD, Peterson TC, Karl TR, Parker DE, Salinger MJ, Razuvayev V, Plummer N, Jamason P, Folland CK (1997) Maximum and minimum temperature trends for the globe. Science 277:364-367

Efron B, Gong G (1983) A leisurely look at the bootstrap, the jacknife, and cross-validation. Am Stat 37:36-48

Fontoin H, Saucier C, Teissedre P, Glories Y (2008) Effect of pH, ethanol and acidity on astringency and bitterness of grape seed tannin oligomers in model wine solution. Food Qual Prefer 19:286-291

Gladstones J (1992) Viticulture and environment. Winetitles, Adelaide

Gladstones J (2011) Wine, terroir and climate change. Wakefield, Adelaide

Godwin DC, White RJG, Sommer KJ, Walker RR, Goodwin I, Clingeleffer PR (2002) VineLOGIC - a model of grapevine growth, development and water use. In: Dundon C, Hamilton R, Johnstone $\mathrm{R}$, Partridge $\mathrm{S}$ (eds) Australian society of viticulture and oenology. Winetitles, Mildura, pp 46-50 
Hall A, Jones G (2009) Effect of potential atmospheric warming on temperature based indices describing Australian winegrape growing conditions. Aust J Grape Wine Res 15:97-119

Haselgrove L, Botting D, Heeswijck R, Høj P, Dry P, Ford C, Land P (2000) Canopy microclimate and berry composition: the effect of bunch exposure on the phenolic composition of Vitis vinifera $\mathrm{L}$ cv. Shiraz grape berries. Aust J Grape Wine Res 6:141-149

Herderich M, Smith P (2005) Analysis of grape and wine tannins: methods, applications and challenges. Aust J Grape Wine Res $11: 205-214$

Iland P, Bruer N, Edwards G, Weeks S, Wilkes E (2004) Chemical analysis of grapes and wine: techniques and concepts. Iland Wine Promotions, Adelaide

Jackson RS (2000) Wine science: principles, practices, perception. Academic, San Diego

Jackson D, Lombard P (1993) Environmental and management practices affecting grape composition and wine quality —a review. Am J Enol Vitic 44:409-430

Jeffrey S, Carter J, Moodie K, Beswick A (2001) Using spatial interpolation to construct a comprehensive archive of Australian climate data. Environ Model Softw 16:309-330

Jones G, Davis R (2000) Climate influences on grapevine phenology, grape composition, and wine production and quality for Bordeaux, France. Am J Enol Vitic 51:249-261

Jones G, Storchmann K (2001) Wine market prices and investment under uncertainty: an econometric model for Bordeaux Crus Classés. Agric Econ 26:115-133

Jones G, White M, Cooper O, Storchmann K (2005) Climate change and global wine quality. Clim Chang 73:319-343

Keller M, Tarara J, Mills L (2010) Spring temperature alter repruductive development in grapevines. Aust J Grape Wine Res 16:445-454

Kliewer WM (1966) Sugars and organic acids of Vitis vinifera. Plant Physiol 41:923-931

Kliewer WM (1977) Influence of temperature, solar radiation and nitrogen on coloration and composition of Emperor grapes. Am J Enol Vitic 28:96-103

Kliewer W, Torres R (1972) Effect of controlled day and night temperatures on grape coloration. Am J Enol Vitic 23:71-77

Kliewer W, Weaver R (1971) Effect of crop level and leaf area on growth, composition, and coloration of Tokay grapes. Am J Enol Vitic 22:172-177

Lobell DB, Field CB, Cahill KN, Bonfils C (2006) Impacts of future climate change on California perennial crop yields: model projections with climate and crop uncertainties. Agric For Meteorol 141:208-218

Makra L, Vitanyi B, Gal A, Mika J, Matyasovszky I, Hirsch T (2009) Wine quantity and quality variations in relation to climatic factors in the Tokaj (Hungary) winegrowing region. Am J Enol Vitic 60:312321

Mori K, Sugaya S, Gemma H (2005) Decreased anthocyanin biosynthesis in grape berries grown under elevated night temperature condition. Sci Hortic 105:319-330

Mori K, Goto-Yamamoto N, Kitayama M, Hashizume K (2007) Loss of anthocyanins in red-wine grape under high temperature. J Exp Bot 58:1935-1945

Mullins M, Bouquet A, Williams L (1992) Biology of the grapevine. Cambridge University Press, Cambridge

Myers R (1992) Classical and modern regression with applications. Duxbury, Boston
Nemani R, White M, Cayan D, Jones G, Running S, Coughlan J, Peterson D (2001) Asymmetric warming over coastal California and its impact on the premium wine industry. Clim Res 19:25-34

Petrie P, Sadras VO (2008) Advancement of grapevine maturity in Australia between 1993 and 2006: putative causes, magnitude of trends and viticultural consequences. Aust J Grape Wine Res 14:3345

Rankine B, Fornachon J, Boehm E, Cellier K (1971) Influence of grape variety, climate and soil on grape composition and on the composition and quality of table wines. Vitis 10:33-50

Ristic R, Downey, MO, Iland PG, Bindon K, Francis IL, Herderich M, Robinson S (2007) Exclusion of sunlight from Shiraz grapes alters wine colour, tannin and sensory properties. Aust J Grape Wine Res $13: 53-65$

Ruhl E (1992) Effect of supply and relative humidity on ion uptake and distribution on two grapevine rootstock varieties. Vitis 31:23-33

Sadras VO, Soar C, Petrie P (2007a) Quantification of time trends in vintage scores and their variability for major wine regions of Australia. Aust J Grape Wine Res 13:117-123

Sadras VO, Stevens R, Pech J, Taylor E, Nicholas P, McCarthy M (2007b) Quantifying phenotypic plasticity of berry traits using an allometric-type approach: a case study on anthocyanins and sugars in berries of Cabernet Sauvignon. Aust J Grape Wine Res 13:72-80

Sivilotti P, Bonetto C, Paladin M, Peterlunger E (2005) Effect of soil moisture availability on Merlot: from leaf water potential to grape composition. Am J Enol Vitic 56:9-18

Smart RE (1985) Principles of grapevine canopy microclimate manipulation with implications for yield and quality. A review. Am J Enol Vitic 36:230-239

Smart RE, Dry PR (1980) A climatic classification for Australian viticultural regions. Aust Grapegrower Winemaker 196:8-12

Smart RE, Smith SM, Winchester RV (1988) Light quality and quantity effects on fruit ripening for Cabernet Sauvignon. Am J Enol Vitic 39:250-258

Soar C, Sadras V, Petrie P (2008) Climate drivers of red wine quality in four contrasting Australian wine regions. Aust J Grape Wine Res 14:78-90

Spayd S, Tarara J, Mee D, Ferguson J (2002) Separation of sunlight and temperature effects on the composition of Vitis vinifera $\mathrm{cv}$. Merlot berries. Am J Enol Vitic 53:171-182

Storchmann K (2005) English weather and Rhine wine quality: an ordered probit model. J Wine Res 16:105-120

Sweetman C, Deluc L, Cramer G, Ford C, Soole K (2009) Regulation of malate metabolism in grape berry and other developing fruits. Phytochemistry 70:1329-1344

Webb L, Whetton P, Barlow E (2007) Modelled impact of future climate change on the phenology of winegrapes in Australia. Aust J Grape Wine Res 13:165-175

Webb L, Whetton P, Barlow E (2008a) Modelling the relationship between climate, winegrape price and winegrape quality in Australia. Clim Res 36:89-98

Webb L, Whetton P, Barlow E (2008b) Climate change and winegrape quality in Australia. Clim Res 36:99-111

Williams RJ, Zerihun A, Montagu KD, Hoffman M, Hutley LB, Chen X (2005) Allometry for estimating aboveground tree biomas in tropical and subtropical eucalypt woodlands: towards general predictive equations. Aust J Bot 53:607-619

Winkler A (1974) General viticulture. University of California Press, Los Angeles 